\title{
Application of new directional logic to improve DC side fault discrimination for high resistance faults in HVDC grids
}

\author{
Naushath M. HALEEM ${ }^{1}$, Athula D. RAJAPAKSE ${ }^{1}$
}

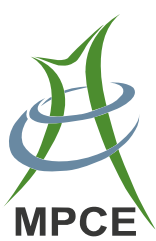

\begin{abstract}
This paper proposes a simple and fast way to determine the direction of a fault in a multi-terminal high voltage direct current (HVDC) grid by comparing the rate of change of voltage (ROCOV) values at either side of the $\mathrm{d} i / \mathrm{d} t$ limiting inductors at the line terminals. A local measurement based secure and fast protection method is implemented by supervising a basic ROCOV relay with a directional element. This directional information is also used to develop a slower communication based DC line protection scheme for detecting high resistance faults. The proposed protection scheme is applied to a multi-level modular converter based three-terminal HVDC grid and its security and sensitivity are evaluated through electromagnetic transient simulations. A methodology to set the protection thresholds considering the constraints imposed by the breaker technology and communication delays is also presented. With properly designed $\mathrm{d} i / \mathrm{d} t$ limiting inductors, the ability of clearing any DC transmission system fault before fault currents exceeds a given breaker capacity is demonstrated.
\end{abstract}

Keywords Directional relay, DC line protection, Multiterminal HVDC grid protection, Rate of change of voltage (ROCOV) based HVDC transmission fault detection

CrossCheck date: 25 May 2017

Received: 14 February 2017/Accepted: 25 May 2017/Published online: 28 June 2017

(C) The Author(s) 2017. This article is an open access publication

Naushath M. HALEEM

umnausha@myumanitoba.ca

Athula D. RAJAPAKSE

athula.Rajapakse@umanitoba.ca

University of Manitoba, Winnipeg, MB, Canada

\section{Introduction}

In order to reduce the impact of electricity generation on alarmingly unfolding climate change, policies have been implemented to increase the use of renewable energy resources for bulk electricity generation. Some of the best resources such as wind and tidal energy are located in offshore sites. High voltage direct current (HVDC) transmission is the only feasible mode of importing energy from large-scale offshore generation sites through long submarine cables [1]. Moreover, the HVDC technology based on voltage source converters (VSCs) can facilitate asynchronous connection between fluctuating and weak energy sources and AC load centers [1]. VSC-HVDC schemes are implemented using the efficient multilevel modular converter (MMC) technology. Multi-terminal HVDC (MTHVDC) grids are proposed to collect energy from geographically dispersed green energy resources and transport to load centers located beyond a single political zone.

There are few MT-HVDC grids which have been commissioned [2, 3], while several others are being planned. However, protection systems of those grids are not capable of preserving the availability of the healthy part of an MTHVDC grid during DC side faults. Unlike in current source converters (CSCs) based on thyristors, the fault currents through the MMCs based on half bridge switching cells cannot be easily interrupted. As any means of controlling fault current via reduction of DC side voltage, fault tolerant convertors such as those proposed in $[4,5]$ are not suitable for large MT-HVDC grids. Such fault current control strategies cause to cease the operation of the whole grid via voltage collapsing. Therefore, DC circuit Breakers (DCCB) such as $[6,7]$ are proposed to clear DC side faults. However, fault current interruption in HVDC transmission circuits is challenging due to rapid rate of rise of currents and 
the absence of zero crossings [8]. Therefore, MT-HVDC grids require ultra-fast fault detection and isolation.

Fault discrimination is a key factor in MT-HVDC grid protection. A boundary inductor, an inductor placed between the converter and the transmission line end, is proposed to lower the rate of rising fault current [9]. Those boundary inductors ease the ability to discriminate faults in adjacent lines up to certain extend [9]. Commonly, the magnitudes of fault indicators observed or derived from terminal measurements are utilized to discriminate faults in the protected line from those on adjacent lines. Fault discrimination has been carried out using the magnitude of observed rate of rise of current [10], magnitude of the rate of change of line side voltage of the boundary inductor $[9,10]$, the time rate of voltage across the boundary inductor [11], or the magnitude of backward travelling wave [12]. However, large discrimination margins are required when the magnitudes of the fault disturbances are used for discriminating the faults, and as a result sensitivity of protection is reduced. Although communication based fault detection schemes such as current differential fault detection [13] and energy based fault detection methods $[14,15]$ are superior in terms of fault discrimination, any fault detection scheme which includes communication is not a likely to be satisfactory for primary protection of MTHVDC grids as communication delays may not be tolerated.

Identification of the direction of a fault with respected the location of the protection relay (here after referred to as fault direction identification) is helpful to enhance the security. Directional relays such as [16] are widely used to improve fault discrimination in AC grids. The most common method of detecting the direction of a fault is comparison of the magnitudes of forward and backward waves which are calculated using both voltage and current measurements $[17,18]$. Current derivatives have been used to discriminate forward and backward faults in [19]. However, both of above methods of detecting direction of fault requires terminal current measurements taken through DC current transformers (CT).

Since a fault created wave attenuates when travelling through a boundary inductor [12], the side of the fault with respect to boundary inductor can be easily and reliably identified if the magnitudes of disturbance at two sides are compared. A number of advantages are apparent in this method when compared with aforementioned methods of fault direction identification. As the rate of change of voltage (ROCOV) based fault detection methods [9, 11] applied for detection of transmission line and bus faults demands both line side voltage and bus side voltages, no additional sensors are necessary. Fault directions can be readily identified without using costly high bandwidth CTs that needed to measure fast current transients. Furthermore, the rate of dropping of voltages during DC side faults is much faster than the rate of rising of fault currents: this is because the rate of rising of current is approximately equals to the time integral of voltage variation. Therefore, a voltage based directional element can detect the direction of a fault promptly when a travelling wave reaches the terminal. Rapid discharge of filter and cable capacitance are dominant during the early phase rising fault current [20]. Since the maximum/steady state fault currents for short circuit faults are likely to be much higher than the circuit breaker capabilities [21], a fault must be detected and the DC circuit breakers (DCCBs) must be opened before the fault current rises above the breaker's maximum interruption current. This aspect has not been tested in the fault detection schemes such as the one presented in [12]. The rate of change of voltage based HVDC grid protection scheme presented in [9] can face difficulties during high resistance faults.

In this paper, a method to identify the direction of a fault using local measurements and a basic arrangement to use the identified fault directions to improve the sensitivity, speed and reliability of the ROCOV based HVDC grid protection scheme described in [9] are presented. As no communication delay is involved, the local measurement based directional protection scheme can detect faults well before the fault currents reach the maximum breakable current. As shown in this paper, discrimination of high resistance faults at the far end of a long cable or transmission line is challenging [22]. To overcome such situations, a double ended ROCOV based directional comparison scheme is also presented.

\section{Test grid and ROCOV based protection}

The three-terminal VSC-HVDC test grid model developed in [9] is utilized in this study. The test grid shown in Fig. 1 is a bipolar-HVDC grid having a metallic return with a single earthing point. This configuration is one of the most likely practical HVDC grid configurations [9].

A bipolar low resistance single earth scheme requires a faster protection scheme than bipolar high resistance

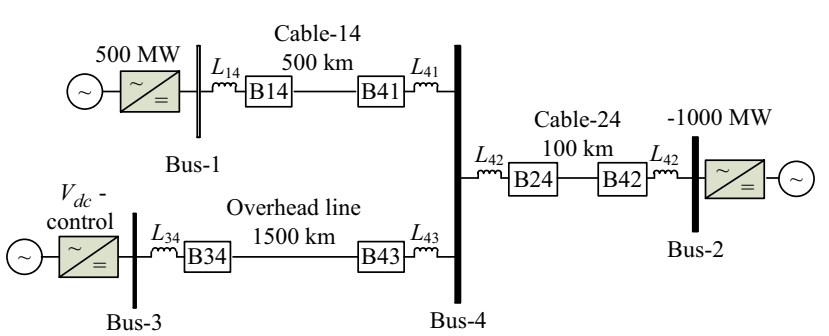

Fig. 1 Structure of the MT-HVDC test grid 
grounding and symmetrical monopole HVDC grids [23]. The test grid includes a long underground cable (Cable-14), a short underground cable (Cable-24), as well as a long overhead line (Line-24) to illustrate contrasting protection challenges. The grid was simulated in PSCAD/EMTDC electromagnetic transient (EMT) simulation software. Parameters of the test grid are shown in Table 1.

The frequency dependent phase domain models available in PSCAD were used to simulate the cables and transmission lines. The simulation time step used is $10 \mu \mathrm{s}$. The MMCs connected to Buses 1, 2 and 3 were modeled with decoupled controls and converter transformers. It was assumed that basic fault protection is provided using the ROCOV based protection proposed in [9]. In this scheme, each line/cable section is protected using DC circuit breakers, and di/dt limiting inductors (also referred to as terminal inductors) placed at either end [24]. These di/ $\mathrm{d} t$ limiting terminal inductors (values given in Table 1) relax the DC circuit breaker requirement and considered as vital for DC breaker application [24]. In simulations, the hybrid DC breaker model described in [6] was used with 2 ms operating delay and a maximum breaker current of 8 $\mathrm{kA}$ as in [9]. The PSCAD surge arrester model with default characteristic and $243 \mathrm{kV}$ rating was used in the hybrid breaker circuit.

\subsection{ROCOV based protection Principle}

Sudden occurrence of high $\mathrm{d} v / \mathrm{d} t$ in the voltage measured between the line side of a terminal inductor and ground is an indication of a transmission line fault $[9,19]$. The fault detection and discrimination algorithm used in [9] is concisely depicted in Fig. 2. The process of selecting $\mathrm{d} v /$ $\mathrm{d} t$ settings is fully described in [9]. Since the fault generated voltage surge attenuate when passing through a di/ $\mathrm{d} t$ limiting inductor, the peak $\mathrm{d} v / \mathrm{d} t$ observed at the line side of terminal inductor is significantly smaller for bus faults and the faults in the adjacent lines, compared to the peak $\mathrm{d} v / \mathrm{d} t$ observed for a fault in the protected line. This feature

Table 1 Test grid details

\begin{tabular}{|c|c|c|c|c|c|c|}
\hline \multicolumn{5}{|l|}{ Parameter } & \multicolumn{2}{|l|}{ Value } \\
\hline \multicolumn{5}{|c|}{ Nominal DC grid power } & \multicolumn{2}{|c|}{$1000 \mathrm{MW}$} \\
\hline \multicolumn{5}{|c|}{ Nominal AC voltage $\left(V_{L L}\right)$} & \multicolumn{2}{|l|}{$230 \mathrm{kV}$} \\
\hline \multicolumn{5}{|c|}{ Nominal DC voltage } & \multicolumn{2}{|c|}{ $\pm 320 \mathrm{kV}$} \\
\hline \multicolumn{5}{|c|}{ Power from converter-1 } & \multicolumn{2}{|c|}{$250 \mathrm{MW} /$ pole } \\
\hline \multicolumn{5}{|c|}{ Power from converter- 2} & \multicolumn{2}{|c|}{$-500 \mathrm{MW} /$ pole } \\
\hline \multicolumn{4}{|c|}{ Power from converter- 3} & & \multicolumn{2}{|c|}{$272 \mathrm{MW} /$ pole } \\
\hline Relay location & R14 & R41 & R24 & R42 & R34 & R43 \\
\hline Inductance $(\mathrm{mH})$ & 125 & 125 & 100 & 100 & 100 & 50 \\
\hline
\end{tabular}

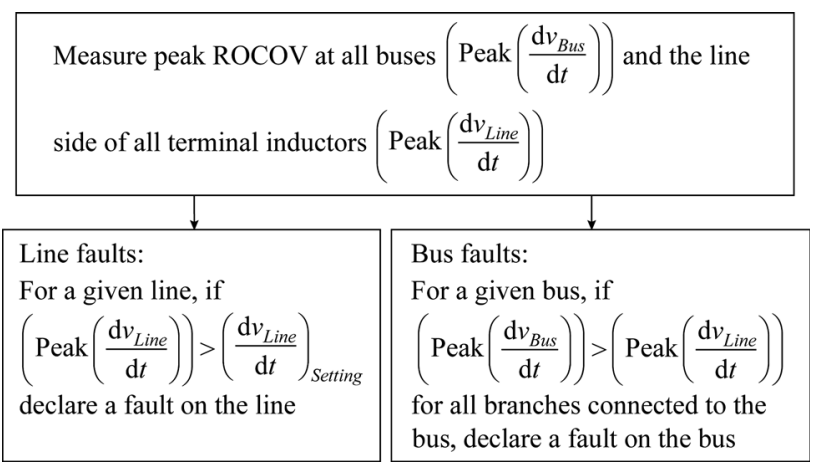

Fig. 2 ROCOV based protection algorithm proposed in [9]

is used to discriminate the line faults from the faults on buses and adjacent branches [9].

A bus fault can be identified by comparing the $\mathrm{d} v /$ $\mathrm{d} t$ values on both sides of the all terminal inductors connected to the bus, as a bus fault generate a higher peak $\mathrm{d} v /$ $\mathrm{d} t$ on the bus side of all terminal inductors.

\subsection{Signal processing in ROCOV based protection}

The performance of a ROCOV based protection scheme can be significantly affected by the sensor bandwidth and the characteristics of the signal processing scheme. Assuming that practical high voltage sensors have at least $8 \mathrm{kHz}$ bandwidth, any effects from the variations in the bandwidth of different sensors and measurement noise were eliminated by low pass filtering the measured voltage signals with a $8 \mathrm{kHz}$ third order Butterworth filter.

Impact of the filtering on two voltage signals, one caused by a nearby fault and the other caused by a faraway fault, is shown in Fig. 3.

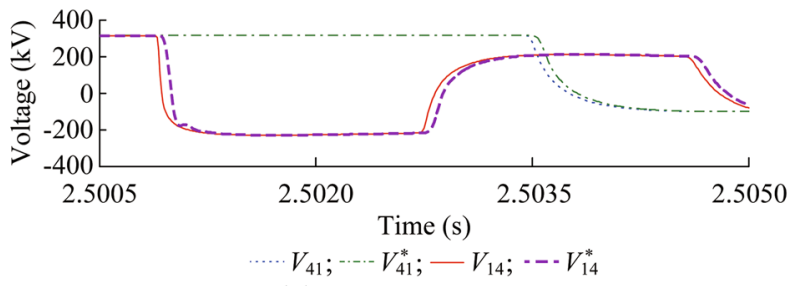

(a) Voltage measurement

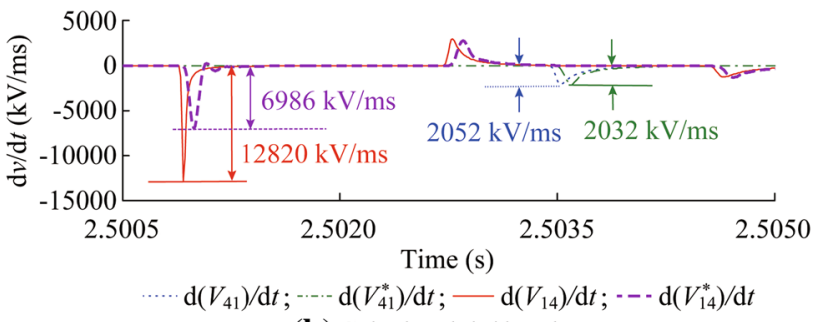

(b) Calculated $\mathrm{d} v / \mathrm{d} t$ values

Fig. 3 Measurements at line side of $L_{14}$ and $L_{41}$ with/without filtering during a solid fault $(0.1 \Omega)$ on Cable-14 at $400 \mathrm{~km}$ away from $L_{14}$ 
According to Fig. 3, when the fault is far from the measurement point, the difference between the peak $\mathrm{d} v /$ $\mathrm{d} t$ values calculated from the filtered $\left(V^{*}{ }_{41}\right)$ and unfiltered $\left(V_{41}\right)$ voltage waveform is negligible. However, for nearby faults, peak $\mathrm{d} v / \mathrm{d} t$ calculated with filtered signal $\left(V^{*}{ }_{14}\right)$ is significantly lower than that obtained from the unfiltered signal $\left(V_{14}\right)$.

Although filtering removes the dependency of peak $\mathrm{d} v /$ $\mathrm{d} t$ on the location of the fault, this does not affect the protection scheme: only the attenuation of voltage transients by the $\mathrm{d} i / \mathrm{d} t$ limiting inductors is important for fault discrimination. This is because it is not required to discriminate between the close up faults and the far end faults on the same line. Initial investigations showed that $8 \mathrm{kHz}$ bandwidth is sufficient to capture the maximum $|\mathrm{d} v / \mathrm{d} t|$ for a far end fault on the shortest cable/overhead line in the test grid considered. The band limited voltage signal is then sampled at $32 \mathrm{kHz}$ (sampling interval $31.25 \mu \mathrm{s}>$ simulation time step $10 \mu \mathrm{s})$ and digitized with 12-bit ADC to make sure difference between peak $\mathrm{d} v / \mathrm{d} t$ before and after the sampling remains less than $5 \%$. ROCOV or $\mathrm{d} v / \mathrm{d} t$ is digitally calculated between two time steps.

\section{Challenges for ROCOV based DC grid protection}

A dependable DC line protection scheme should be capable of detecting a fault at any point on the protected line regardless of the fault resistance. The faults must be detected and discriminated very quickly because if the fault current rises above the maximum breaker current, fault current cannot be interrupted subsequently. Furthermore, a secure protection scheme should not unnecessarily trip a circuit breaker. The setting of the ROCOV based DC line protection scheme in [9] is a compromise between these two aspects. When the threshold value of peak $\mathrm{d} v / \mathrm{d} t$ is set higher, the operation is more secure, but fails to detect high resistance faults, especially when they are far from the relay. In the following sections, it is shown through simulations of the test MT-HVDC grid in Fig. 1 that a purely ROCOV based DC line protection strategy can fail for certain line faults.

All simulations were performed in PSCAD/EMTDC with a simulation time step of $10 \mu$ s and the fault was applied when $t=2.5 \mathrm{~s}$ in each simulation case. In the analysis, single pole to ground faults (negative pole to ground, for illustration purpose negative pole voltage is measured by keeping the reference probe on the ground and tip on the negative pole so that a fault shows a drop in voltage) were considered, because independent protection design for each pole is expected to be common in DC grid protection [25] and the pole to ground faults are considered as significantly more frequent [26]. The impact of the signal processing circuit used for capturing peak $\mathrm{d} v / \mathrm{d} t$ was also taken in to account. All voltages are measured with respect to the ground.

\subsection{High resistance faults at far end of a line}

In order to examine the response of the typical ROCOV based protection scheme for faults with fairly high fault resistance, a fault having $6 \Omega$ resistance is applied on Cable-14 at a point $450 \mathrm{~km}$ away from breaker B41. With the suggested ROCOV setting of $800 \mathrm{kV} / \mathrm{ms}$ for the breakers B14 and B41 as in [9], the expected response was obtained using the test grid model simulated in PSCAD/ EMTDC. Fig. 4a shows the variations of voltages at line side of the $\mathrm{d} i / \mathrm{d} t$ limiting inductors at Bus- 1 and Bus- 4 (labeled as $V_{14}$ and $V_{41}$ respectively).

The corresponding calculated $\mathrm{d} v / \mathrm{d} t$ values are shown in Fig. $4 \mathrm{~b}$. The peaks in $\mathrm{d} v / \mathrm{d} t$ values correspond with the arrival of travelling waves. According to simulation results, the relay at breaker B14 generates a trip signal because the observed peak $\mathrm{d} v / \mathrm{d} t$ is greater than its setting. As shown in Fig. 5, the breaker B14 breaks the fault current before current through the relay reaches to its maximum breakable current $8 \mathrm{kA}$.

According to Fig. $4 \mathrm{~b}$, the peak $\mathrm{d} v / \mathrm{d} t$ seen at breaker B 41 for the same fault is $790 \mathrm{kV} / \mathrm{ms}$, which is less than its ROCOV setting $800 \mathrm{kV} / \mathrm{ms}$. Therefore, no trip signal is generated for the breaker B41 to clear the fault (non-detection zone). However, the fault current eventually exceeds the maximum breakable current of breaker B41, about 126 ms after the fault as can be seen in Fig. 5 .

This simulation case demonstrates that simple ROCOV based protection scheme can fail to operate for high resistance faults far from the relay point. Since the peak $\mathrm{d} v /$ $\mathrm{d} t$ values observed by a relay during a fault are dependent on the location as well as the resistance of the fault, it is

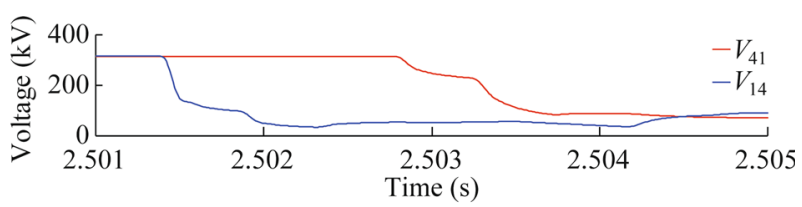

(a) Voltages at Bus-1 and Bus- 4 on the cable side of $L_{14}$ and $L_{41}$

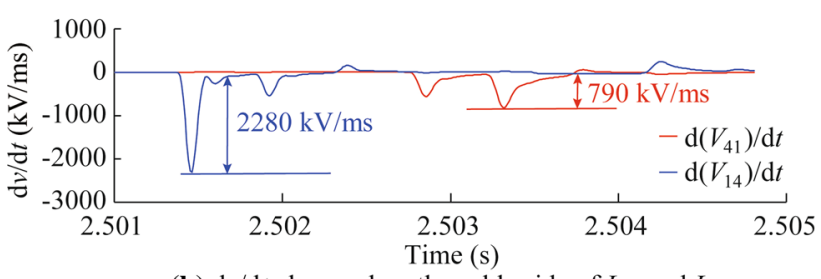

(b) $\mathrm{d} v / \mathrm{d} t$ observed on the cable side of $L_{14}$ and $L_{41}$

Fig. 4 Measurements at a $6 \Omega$ fault on Cable-14 at $450 \mathrm{~km}$ away from B41 


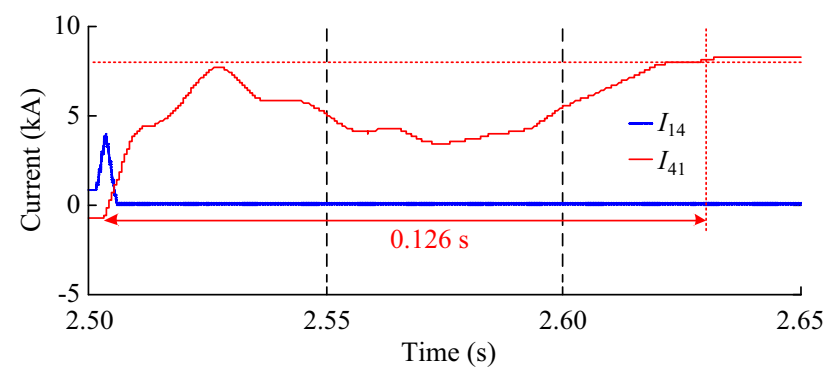

Fig. 5 Calculated negative-pole conductor current through B14 and B41

possible to construct a surface plot of peak $|\mathrm{d} v / \mathrm{d} t|$ as in Fig. 6.

The plot in Fig. 6 was generated for Cable-14 in the test grid. The setting of the ROCOV relay can be shown as a plane on the same plot. The faults with distance -resistance combinations resulting in peak $|\mathrm{d} v / \mathrm{d} t|$ values below the plane of the setting will not be detected.

\subsection{Impact of external Events}

In addition to the faults in the protected line, there are other external events such as faults on the adjacent lines and opening of circuit breakers protecting the adjacent lines cause high values of $\mathrm{d} v / \mathrm{d} t$ at the measurement point of a ROCOV relay. To avoid inadvertent operation of the relay for such external events, ROCOV threshold need to be set sufficiently above the highest value of $\mathrm{dv} / \mathrm{dt}$ observed due to external events. First, the impact of external faults on the operation B43 (on overhead line) is examined by disabling the operation of breakers B14 and B41 for a $0.1 \Omega$ fault on Cable-14 at $50 \mathrm{~km}$ away from $\mathrm{B} 41$. The $\mathrm{d} v / \mathrm{d} t$ values observed at B41, B43 and Bus-4 are shown in Fig. 7. The peak $\mathrm{d} v / \mathrm{d} t$ observed at B43 is $632 \mathrm{kV} /$ $\mathrm{ms}$ as indicated on the graph. Next, the impact of opening of breaker B41 on the operation of relay at B43 is examined by repeating the simulation without disabling the breakers B14 and B41. This time a high resistance fault of $5 \Omega$ is applied on Cable-41, $400 \mathrm{~km}$ away from B41.The observed $\mathrm{d} v / \mathrm{d} t$ values are shown in Fig. 8 with the respective peak values. A peak $\mathrm{d} v / \mathrm{d} t$ value of $643 \mathrm{kV} / \mathrm{ms}$

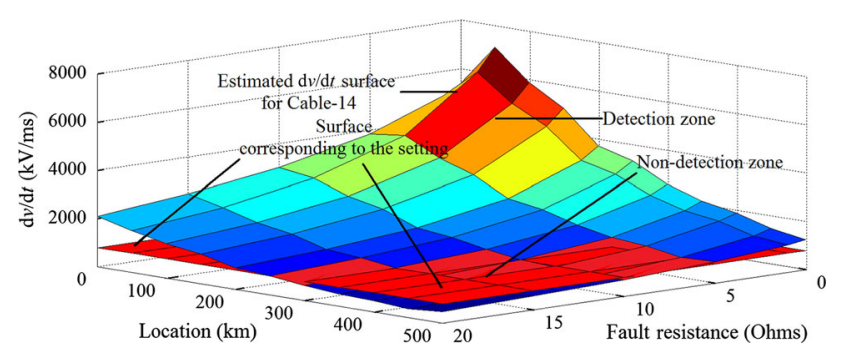

Fig. 6 Peak $|\mathrm{d} v / \mathrm{d} t|$ surface of Cable-14

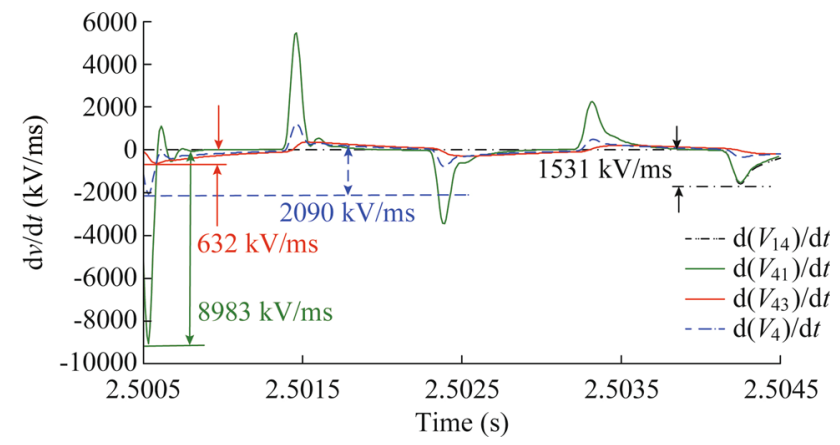

Fig. 7 Peak $\mathrm{d} v / \mathrm{d} t$ values of $V_{14}, V_{41}, V_{43}$, and $V_{4}$ for a $0.1 \Omega$ fault at $50 \mathrm{~km}$ away from B41 on Cable-14

appears at B43 when the breaker B41 opened to clear the fault. The peak $\mathrm{d} v / \mathrm{d} t$ of transient caused by the fault (between $2.5035 \mathrm{~s}$ and $2.504 \mathrm{~s}$ ) is much smaller than this value.

The results presented in Fig. 7 and Fig. 8 show that the peak $\mathrm{d} v / \mathrm{d} t$ created when opening an adjacent breaker has the same degree of impact as a solid close up fault in an adjacent line. In this particular case, if the threshold for relay at B43 is set only considering the peak $\mathrm{d} v / \mathrm{d} t$ values due to faults, it may malfunction during the opening of breaker B41. Some measures need to be taken to improve the security of protection during external events $[9,10]$.

\section{Augmenting ROCOV based DC line protection with directional characteristics}

Two potential vulnerabilities of the simple ROCOV based DC grid protection proposed in [9] and possible challenges in selecting protection settings were illustrated: (1) higher ROCOV settings can cause non-detection of high resistance faults far from the relay point as described in Section 3.1, (2) a lower ROCOV settings can cause false tripping during the opening of breakers protecting adjacent lines as described in Section 3.2. In order to overcome the above mentioned shortcomings, it is proposed to augment the basic ROCOV based protection scheme with additional

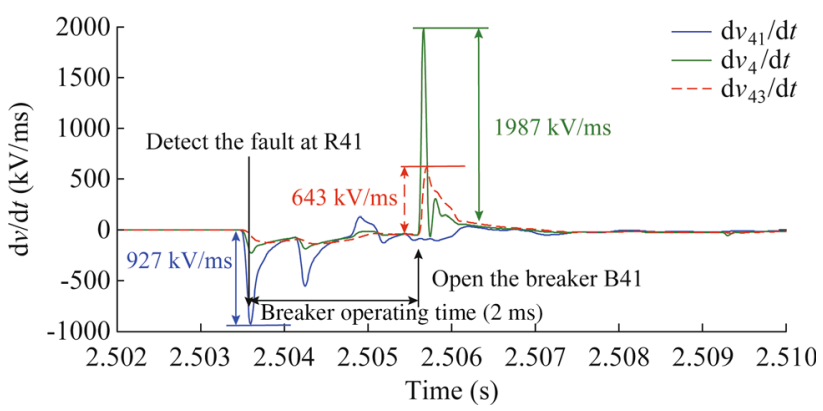

Fig. 8 Peak $\mathrm{d} v / \mathrm{d} t$ values of $V_{14}, V_{41}, V_{43}$, and $V_{4}$ for a $5 \Omega$ fault on Cable-14, $400 \mathrm{~km}$ away from Bus-4 and subsequent opening of B41 
supervision by an under voltage element and by incorporating directional properties to the ROCOV relay through local and remote measurements. Supervision with under voltage elements helps avoiding false operation of ROCOV based detection due to noise in sensing and signal processing circuits [16].

If the ROCOV relay can be supervised by a directional signal that indicates faults in the forward direction, the ROCOV settings can be lowered to cover high resistant faults without reducing the security. Such a directional relay will not be affected by the high $\mathrm{d} v / \mathrm{d} t$ created during the opening of circuit breakers in the reverse direction. Furthermore, the directional ability greatly simplifies the coordination of settings.

Fortunately, there is a simple method to accurately determine the fault direction with respect to a di/d $t$ limiting terminal inductor (relay location) using only the local signals. For practical overhead lines and cables, a fault generated voltage wave propagating along the line is mostly reflected at the terminal inductor [16]. The transmitted component is much smaller. Therefore:

1) the peak $|\mathrm{d} v / \mathrm{d} t|$ observed at the line side of terminal inductor is much greater than that observed at the bus side when the voltage wave is initiated from a fault on the protected line.

2) the peak $|\mathrm{d} v / \mathrm{d} t|$ observed at the line side of terminal inductor is much smaller than that observed at the bus side for faults on the bus or lines behind the inductor location.

Therefore, the fault direction with respect to a relay location can be determined by comparing the magnitudes of peak $|\mathrm{d} v / \mathrm{d} t|$ values observed at either side of the terminal inductor associated with the respective breaker.

For example, consider the simulation results shown in Fig. 7 for a fault on Cable-14. The corresponding peak $\mid \mathrm{d} v /$ $\mathrm{d} t \mid$ values observed at the measurement points near Bus-4 and Bus-1 are shown in Fig. 9.

The peak $|\mathrm{d} v / \mathrm{d} t|$ observed at line side of $L_{41}$ is more than four time times the peak $|\mathrm{d} v / \mathrm{d} t|$ observed on Bus- 4 , indicating that fault is in the direction of Cable-41. The

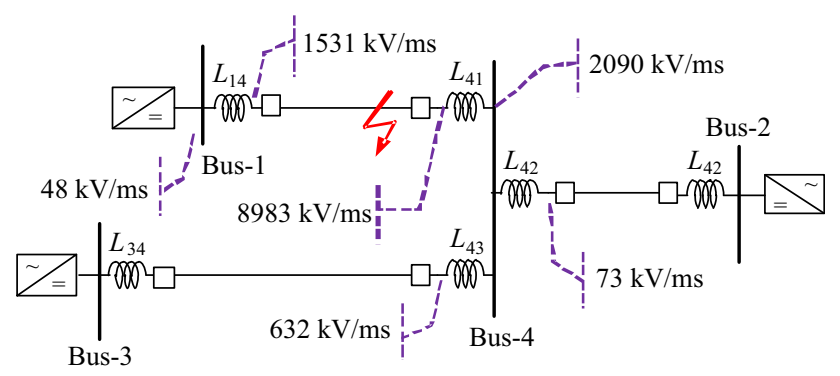

Fig. 9 Peak $|\mathrm{d} v / \mathrm{d} t|$ values for a fault $50 \mathrm{~km}$ away from $L_{41}$ on Cable14 observed peak $|\mathrm{d} v / \mathrm{d} t|$ at Bus-4 is about twenty eight times greater than that observed at the line side of $L_{42}$. Thus the fault is not in the direction of Cable-42. Similarly the peak $|\mathrm{d} v / \mathrm{d} t|$ measurements across $L_{43}$ confirm that fault is not in the direction of Line-43. At the other end of the faulted cable, the peak $|\mathrm{d} v / \mathrm{d} t|$ observed on line side of $L_{14}$ is much higher than that observed on Bus-1, indicating that the fault is in the direction of Cable-41. The decision process of the new ROCOV based protection solution can be explained considering a generic bus (labeled as Bus-Y) in a HVDC grid, as shown in Fig. 10. The notations for various voltage signals, lines, and breakers are indicated on the diagram. Any fault in the direction of the protected line from a breaker is defined as a forward fault and a fault on the bus side from a breaker is defined as a reverse fault. For example, faults on both Line-XY and Line-YP are forward faults for relay associated with breaker BXY whereas a fault on Line-XY is in the reverse direction for the relay associated with breaker BYP.

\subsection{Local measurement based directional ROCOV relay}

Figure 11 shows the scheme proposed to implement the proposed directional ROCOV relay for line/cable protection. The relay protecting Line-XY only uses local measurements available at Bus-Y.

The peak $|\mathrm{d} v / \mathrm{d} t|$ at line side of the terminal inductor is compared with threshold "High-setting", and the

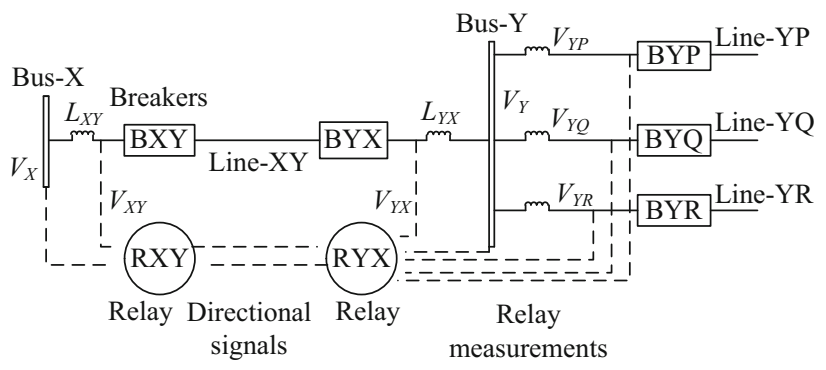

Fig. 10 Notations and voltage measurements utilized at relays

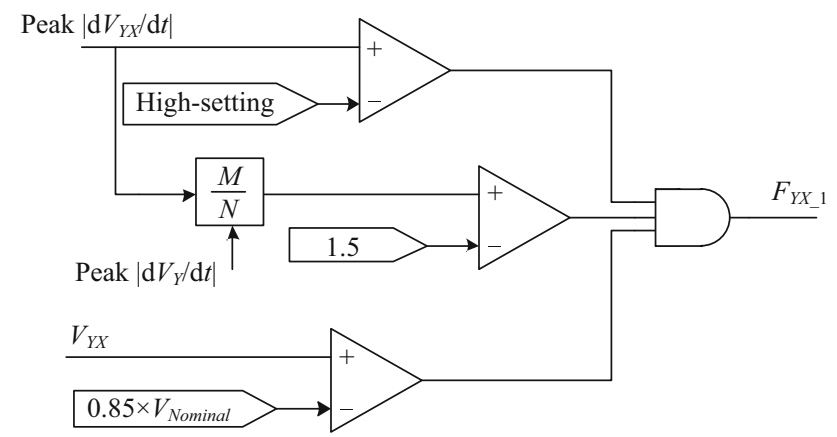

Fig. 11 Local measurement based directional ROCOV scheme 
comparator output is supervised by the proposed directional signal. The directional element calculates the ratio between the peak $|\mathrm{d} v / \mathrm{d} t|$ values observed at the line and bus sides of the terminal inductor $L_{Y X}$. If this ratio is greater than one, theoretically the fault is in the direction of the protected line. However, to increase the security, the direction is declared as forward only if the ratio of peak $|\mathrm{d} v|$ $\mathrm{d} t \mid$ values is greater than 1.5. In addition to the direction, output is also supervised by an under voltage element to enhance the security $[19,23]$. The ROCOV threshold "High-setting" in this scheme can be set lower than a nondirectional ROCOV relay [9]. The lower limit of the "High-setting" is dictated by the peak $|\mathrm{d} v / \mathrm{d} t|$ created at the relay point during a solid fault on the remote bus in the forward direction. For example, "High-setting" of relay RYX should be higher than the peak $|\mathrm{d} v / \mathrm{d} t|$ recorded for a fault on Bus-X.

\subsection{Communication based high resistance fault detector}

As the minimum value of "High-setting" in the local measurements based directional ROCOV relay is constrained, it may not be able to detect faults with a significantly high resistance. This happens when the peak $|\mathrm{d} v / \mathrm{d} t|$ observed at the relay (on line side of terminal inductor) during high resistance fault is less than the peak $|\mathrm{d} v / \mathrm{d} t|$ values caused by a solid remote bus fault. In order to deal with such significantly high resistance faults, a communication assisted ROCOV based directional comparison scheme is proposed.

In this scheme, the relay at one end of the line determines whether the fault is in the forward direction with respect to it, and communicates that information to the other end if the peak $|\mathrm{d} v / \mathrm{d} t|$ observed at the line side of the terminal inductor is above a minimum threshold. A trip signal is issued when both relays indicate that the fault is in the forward direction. There is no supervision by under voltage in this scheme, because for very high resistance faults there may not be a significant low voltage. Figure 12 shows the logic scheme for generating the direction signal using relay RYX as an example.

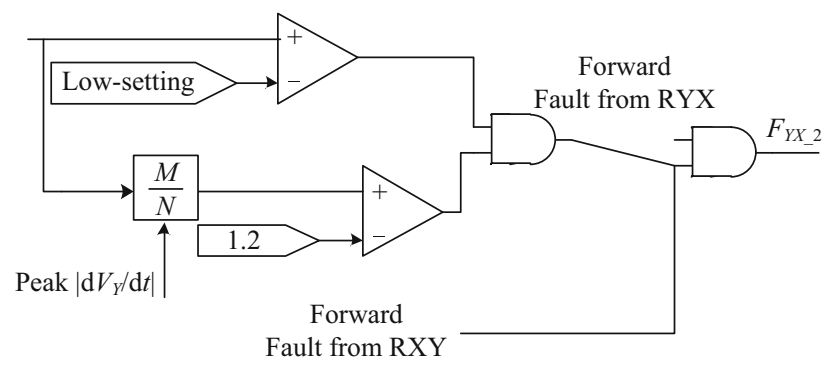

Fig. 12 Communication based high resistance fault detector
Direction is determined similar to the previous case by comparing the ratio of peak $|\mathrm{d} v / \mathrm{d} t|$ values across the terminal inductor $\left(L_{Y X}\right)$ with a threshold of 1.2. The threshold was set slightly lower because the ratio between line side and bus side peak $|\mathrm{d} v / \mathrm{d} t|$ values tend to be lower for high resistance faults due to absence of high frequency components in the transients generated by these faults. Directional signal is enabled only if the peak $|\mathrm{d} v / \mathrm{d} t|$ observed at the line side of $L_{Y X}$ is larger than the threshold "Lowsetting". Although communication based protection schemes cannot be used to protect HVDC transmission from low resistance faults due to high rate of rising current [10], communication delay can be tolerated in the case of high resistance faults which cause a slower rate of rise of current. For example, in the simulation results shown in Fig. 5, the fault current takes about $126 \mathrm{~ms}$ to exceed the limit of breaker B41. This gives sufficient time to apply a communication based protection with no additional cost as communication between convertor stations is expected to be an integral part of future HVDC grids [25]. The two line fault detection schemes operating in parallel satisfy both reliability and speed requirements for a range of fault resistances.

\subsection{ROCOV Comparison Based Bus Fault Detection}

As mentioned before, the voltage disturbance created by a bus fault is highly attenuated when it is passing through the $\mathrm{d} i / \mathrm{d} t$ limiting inductors at line ends. Therefore, the rate of change of bus voltage is much greater than the rate of change of voltages measured at the line sides of the dil $\mathrm{d} t$ limiting inductors. Thus, for all lines emanating from a bus, if the $\mathrm{d} v / \mathrm{d} t$ values observed at line side of the inductors are smaller than the $\mathrm{d} v / \mathrm{d} t$ observed on the bus, a bus fault can be declared. This bus fault detection logic is shown in Fig. 13. To improve the security, a fault is declared only if the maximum $\mathrm{d} v / \mathrm{d} t$ value observed at the bus is greater than Setting_B. This fault detection logic can be supervised by an under voltage element to further improve the security as in $[19,22]$. Drop of bus voltage below VB_Setting confirms the occurrence of a bus fault. Although a number of voltage measurements are taken to detect a bus fault, all measurements are local and no additional delays. The breaker BYX opens when $F_{Y X_{1}}$, $F_{Y X_{-} 2}$, or $F_{B u s-Y}$ becomes TRUE.

\section{Protection Settings and Coordination}

The $\mathrm{d} i / \mathrm{d} t$ limiting inductors at the line ends performs a key role in the proposed protection scheme for discrimination of faulted zones. Thus the DC grid design should be done in conjunction with its protection design. The 


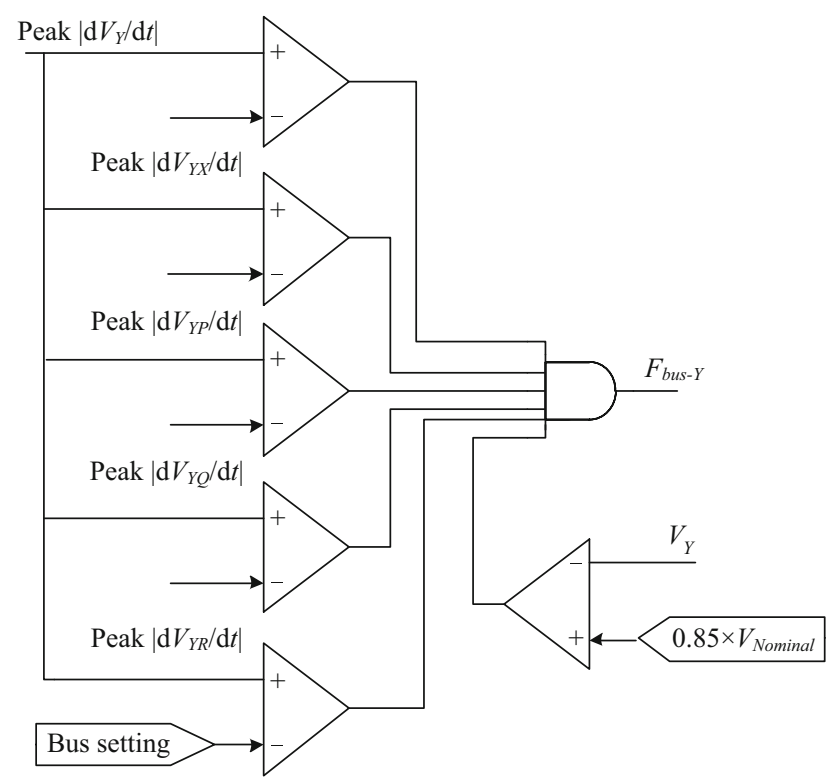

Fig. 13 Bus fault detection logic

terminal inductors should be determined considering the breaker constraints (this paper considers $8 \mathrm{kA}$ maximum breaking current and $2 \mathrm{~ms}$ maximum operating time [6]). An initial guess for terminal inductance is found by applying a solid fault at the line end of the inductor and at the critical distance defined in [9] (distance travelled by waves along the cable or overhead line within half the breaker operating time). The simulations must be used to verify that selected terminal inductances ensure that the fault currents do not exceed the breaker limit within the maximum breaker operating time. The terminal inductors values given in Table 1 were calculated using the above procedure.

The thresholds for the under voltage elements supervising the fault detection schemes are to $85 \%$ of the nominal DC voltage as in [19]. The observations used to calculate the "High-setting" values are shown in Table 2. The aim is to protect the entire transmission line using the local measurement based directional ROCOV relay protection scheme for short circuit faults. Thus the peak $|\mathrm{d} v / \mathrm{d} t|$ for a solid fault at the far end of the protected line is recorded. Then the peak $|\mathrm{d} v / \mathrm{d} t|$ values observed for a solid fault on the remote bus (in forward direction) and that observed when clearing the fault are recorded. Sometimes, the peak $|\mathrm{d} v / \mathrm{d} t|$ observed when clearing the fault is higher than that observed when the fault occurs. The threshold "High-setting" is found by rounding up the result of (1).

$H i g h \_s e t t i n g=A-0.3[A-\max (B$ or $C)]$

$A, B$ and $C$ in (1) are column labels in Table 2.

In a $\pm 320 \mathrm{kV}$ DC grid, any fault with resistance higher than $40 \Omega$ will not result in steady state current above the breaker maximum current. Any faults with higher resistance can be protected using slower differential schemes or over current magnitude relays. The "Low-setting" should be selected to make sure any fault that could exceeds the breaker maximum current is detected and cleared in time. Leaving some margin, "Low-settings" are set to cover faults with up to $50 \Omega$ resistance in this example. Thus the "Low-setting" for the cables is set at $75 \%$ of the observed peak $|\mathrm{d} v / \mathrm{d} t|$ for a $50 \Omega$ fault at far end of the protected line. Although cable faults are usually low resistance in nature, the high resistance fault protection is provided for all cables so that any eventuality covered. The "Low-setting" of the overhead lines can be set to cover higher fault resistance due to low attenuation of travelling waves. Thus "Low-setting" for overhead lines is fixed at $75 \%$ of the peak $|\mathrm{d} v / \mathrm{d} t|$ observed for a $200 \Omega$ fault at far end of the protected line. This is beneficial as high impedance faults are more likely in overhead lines. The "Low-setting" values calculated for each relay is shown in Table 3.

Table 3 Low settings line protection and bus settings

\begin{tabular}{lrrrrrr}
\hline Relay location & R14 & R41 & R24 & R42 & R34 & R43 \\
\hline Low-setting (kV/ms) & 200 & 200 & 950 & 950 & 1450 & 1500 \\
Bus-setting (kV/ms) & 1000 & 4800 & 1000 & 4800 & 200 & 4800 \\
\hline
\end{tabular}

Table 2 High-settings for line protection

\begin{tabular}{|c|c|c|c|c|c|}
\hline \multirow[t]{2}{*}{ Relay } & \multicolumn{3}{|l|}{ Peak $|\mathrm{d} v / \mathrm{d} t|(\mathrm{kV} / \mathrm{ms})$} & \multirow{2}{*}{$\begin{array}{l}\text { Setting from } \\
\text { (1) }(\mathrm{kV} / \mathrm{ms})\end{array}$} & \multirow{2}{*}{$\begin{array}{l}\text { Final "High } \\
\text { setting" }(\mathrm{kV} / \mathrm{ms})\end{array}$} \\
\hline & $\begin{array}{l}\text { For a solid fault at far end of } \\
\text { the protected line }(A)\end{array}$ & $\begin{array}{l}\text { For a solid fault at the remote bus } \\
\text { in forward direction }(B)\end{array}$ & $\begin{array}{l}\text { When clearing remote bus fault } \\
\text { in forward direction }(C)\end{array}$ & & \\
\hline $\mathrm{R} 14$ & 1245 & 48 & 24 & 407 & 450 \\
\hline $\mathrm{R} 41$ & 1269 & 48 & 24 & 414 & 450 \\
\hline R24 & 6275 & 97 & 76 & 1950 & 1950 \\
\hline R42 & 6307 & 102 & 51 & 1964 & 2000 \\
\hline R34 & 3516 & 1318 & 2246 & 2627 & 2650 \\
\hline R43 & 3589 & 634 & 488 & 1538 & 1550 \\
\hline
\end{tabular}


The threshold "Bus-setting" is set below the peak $|\mathrm{d} v / \mathrm{d} t|$ observed during a $50 \Omega$ on the protected bus, and above the highest peak $|\mathrm{d} v / \mathrm{d} t|$ observed during the opening of breakers in adjacent lines or during the faults on remote converter buses. Exception is the bus at which metallic return wire is grounded. If the metallic return is grounded close to a bus, that bus can be more effectively protected using overcurrent or $\mathrm{d} i / \mathrm{d} t$ relays, as peak $|\mathrm{d} v / \mathrm{d} t|$ measured at such a bus (example bus-3 in test system) would not change significantly due to strong dc sources (VSCs) connected between the ground and poles. For example, if "Bus-setting" for Bus-3 is set at $200 \mathrm{kV} / \mathrm{ms}$, it can only detect faults with a resistance of $4 \Omega$ or less. If the fault current rises above the breaker limit within the operating delay of the communication based scheme (direction detection time + communication delay + breaker operating time), the value of the terminal inductors of the line need to be increased or the safety margin of "High-setting" of the local measurement based schemes need to be decreased. In this paper, the communication delay $\left(T_{D}\right.$ in $\mathrm{ms}$ ) is approximately modeled as:

$T_{D}=5+0.5 v_{o} l_{t x}$

where $v_{o}$ is the velocity of light in free space $(\mathrm{km} / \mathrm{ms})$ and $l_{t x}$ is length of the line $(\mathrm{km})$. The constant term in (2) represents the processing delays in equipment while the second term represents the signal travel time. Speed of wave propagation in communication media is assumed half of the speed of light, which is a worst case scenario [13]. It is required to test whether the settings are satisfactory under both directions of power flows (if allowed). This is because the time taken by fault currents to rise above the maximum breakable current depends on the direction of pre-fault load currents. If any inductor value is decreased, the all settings need to be re-evaluated.

\section{Validation}

The proposed ROCOV based protection scheme was implemented for the simple $\pm 320 \mathrm{kV}$ HVDC grid system presented in Section 2, with the settings in Tables 2 and 3. Simulation model in PSCAD/EMTDC included sufficient details including the signal processing blocks. In order to demonstrate the operation and need for the communication based protection scheme, a $60 \Omega$ fault was applied on the overhead line (Line-34), $1200 \mathrm{~km}$ away from B34. Some illustrative results are shown in Figs. 14 and 15.

The local measurement based protection scheme at B43 declares a transmission line fault as the observed peak $\mid \mathrm{d} v /$ $\mathrm{d} t \mathrm{l}, \quad 3223 \mathrm{kV} / \mathrm{ms}$ is higher than the "High-setting" $(1550 \mathrm{kV} / \mathrm{ms})$, and the direction is found to be forward. Also, detection of forward fault is communicated to the

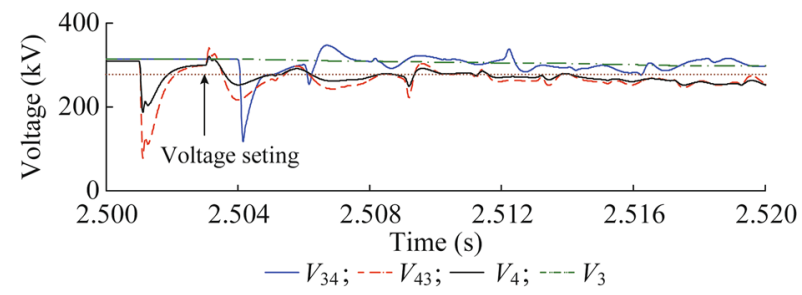

(a) Voltages at line side of terminal inductors at B34 and B43 and Bus-4

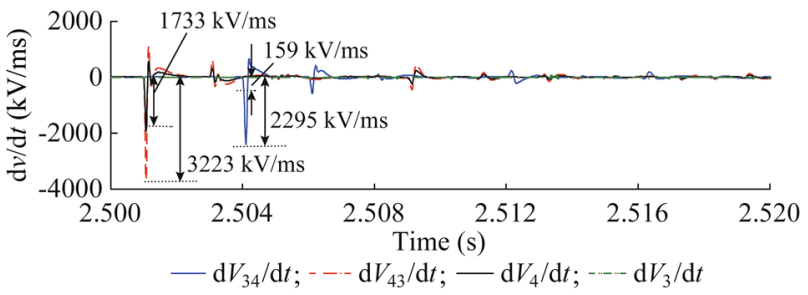

(b) Corresponding $\mathrm{d} v / \mathrm{d} t$ values

Fig. 14 Measurements during a $60 \Omega$ fault on OHL-34 at $1200 \mathrm{~km}$ away from B34

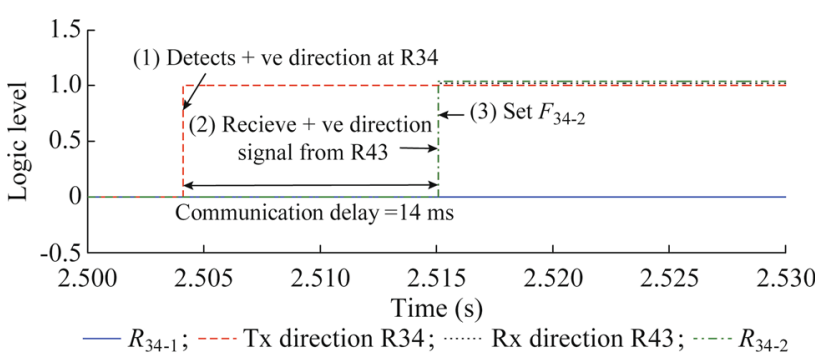

(a) Signals at R34

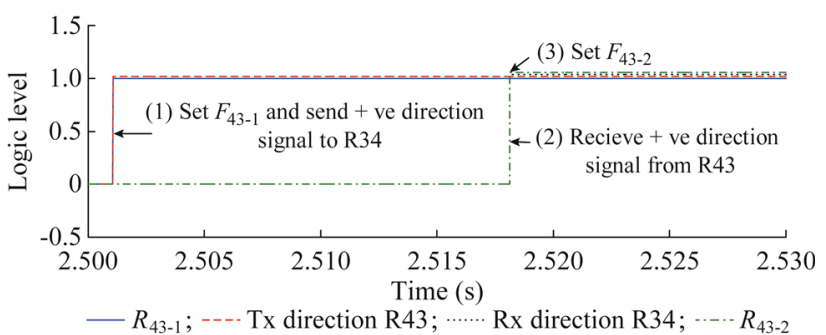

(b) Signals at R43

Fig. 15 Signals at R34 and R43

remote relay at B34. Since the peak $|\mathrm{d} v / \mathrm{d} t|$ observed at B34 $(2295 \mathrm{kV} / \mathrm{ms})$ is lower than the "High-setting" of R34 $(2650 \mathrm{kV} / \mathrm{ms})$, the local measurement based ROCOV unit at R34 did not detect this fault. However, directional element of the communication based scheme in R34 detects a forward fault, and the observed peak $|\mathrm{d} v / \mathrm{d} t|$ is above its "Low-setting" (1450 kV/ms). Thus upon reception of the directional signal from R43 at the other end, occurrence of a fault in the protected line was confirmed.

The fault detection capability, satisfaction of breaker constraints, and mal-operation of proposed protection schemes are evaluated for different faults on the test HVDC grid. Table 4 summarizes the performance of the combined protection scheme for faults on overhead line. 
Table 4 Protection performance during faults on overhead line

\begin{tabular}{|c|c|c|c|c|c|c|c|c|c|c|c|}
\hline \multirow[t]{3}{*}{ Distance from Bus-3 (km) } & \multirow[t]{3}{*}{$R_{F}(\Omega)$} & \multicolumn{3}{|c|}{ Peak $\mathrm{d} v / \mathrm{d} t(\mathrm{kV} / \mathrm{ms})$ of } & \multicolumn{4}{|c|}{ Fault detection } & \multicolumn{2}{|c|}{ Max current limit } & \multirow[t]{3}{*}{ S } \\
\hline & & \multirow[t]{2}{*}{$V_{34}$} & \multirow[t]{2}{*}{$V_{43}$} & \multirow[t]{2}{*}{$V_{4}$} & \multicolumn{2}{|c|}{ R34 } & \multicolumn{2}{|c|}{$\mathrm{R} 43$} & \multirow[t]{2}{*}{$I_{R 34}$} & \multirow[t]{2}{*}{$I_{R 43}$} & \\
\hline & & & & & 1 & 2 & 1 & 2 & & & \\
\hline \multirow[t]{3}{*}{0} & 0.05 & 5421 & 3589 & 1880 & $\sqrt{ }$ & $\sqrt{ }$ & $\sqrt{ }$ & $\sqrt{ }$ & $\sqrt{ }$ & $\sqrt{ }$ & $\sqrt{ }$ \\
\hline & 60 & 4420 & 2930 & 1538 & $\sqrt{ }$ & $\sqrt{ }$ & $\sqrt{ }$ & $\sqrt{ }$ & $\sqrt{ }$ & $\sqrt{ }$ & $\sqrt{ }$ \\
\hline & 200 & 3052 & 1978 & 1050 & $\sqrt{ }$ & $\sqrt{ }$ & $\sqrt{ }$ & $\sqrt{ }$ & $\sqrt{ }$ & $\sqrt{ }$ & $\sqrt{ }$ \\
\hline \multirow[t]{4}{*}{300} & 0.05 & 4566 & 3223 & 1684 & $\sqrt{ }$ & $\sqrt{ }$ & $\sqrt{ }$ & $\sqrt{ }$ & $\sqrt{ }$ & $\sqrt{ }$ & $\sqrt{ }$ \\
\hline & 20 & 4029 & 2832 & 1514 & $\sqrt{ }$ & $\sqrt{ }$ & $\sqrt{ }$ & $\sqrt{ }$ & $\sqrt{ }$ & $\sqrt{ }$ & $\sqrt{ }$ \\
\hline & 110 & 2661 & 1904 & 1001 & $\sqrt{ }$ & $\sqrt{ }$ & $\sqrt{ }$ & $\sqrt{ }$ & $\sqrt{ }$ & $\sqrt{ }$ & $\sqrt{ }$ \\
\hline & 175 & 2148 & 1538 & 805 & $\mathrm{x}$ & $\sqrt{ }$ & $\mathrm{x}$ & $\sqrt{ }$ & $\sqrt{ }$ & $\sqrt{ }$ & $\sqrt{ }$ \\
\hline \multirow[t]{5}{*}{750} & 0.05 & 3809 & 3809 & 2026 & $\sqrt{ }$ & $\sqrt{ }$ & $\sqrt{ }$ & $\sqrt{ }$ & $\sqrt{ }$ & $\sqrt{ }$ & $\sqrt{ }$ \\
\hline & 20 & 3369 & 3369 & 1807 & $\sqrt{ }$ & $\sqrt{ }$ & $\sqrt{ }$ & $\sqrt{ }$ & $\sqrt{ }$ & $\sqrt{ }$ & $\sqrt{ }$ \\
\hline & 60 & 2735 & 2759 & 1465 & $\sqrt{ }$ & $\sqrt{ }$ & $\sqrt{ }$ & $\sqrt{ }$ & $\sqrt{ }$ & $\sqrt{ }$ & $\sqrt{ }$ \\
\hline & 110 & 2246 & 2222 & 1172 & $\mathrm{x}$ & $\sqrt{ }$ & $\sqrt{ }$ & $\sqrt{ }$ & $\sqrt{ }$ & $\sqrt{ }$ & $\sqrt{ }$ \\
\hline & 175 & 1807 & 1807 & 952 & $\mathrm{x}$ & $\sqrt{ }$ & $\sqrt{ }$ & $\sqrt{ }$ & $\sqrt{ }$ & $\sqrt{ }$ & $\sqrt{ }$ \\
\hline \multirow[t]{4}{*}{1200} & 0.05 & 3174 & 4542 & 2393 & $\sqrt{ }$ & $\sqrt{ }$ & $\sqrt{ }$ & $\sqrt{ }$ & $\sqrt{ }$ & $\sqrt{ }$ & $\sqrt{ }$ \\
\hline & 20 & 2808 & 4029 & 2124 & $\sqrt{ }$ & $\sqrt{ }$ & $\sqrt{ }$ & $\sqrt{ }$ & $\sqrt{ }$ & $\sqrt{ }$ & $\sqrt{ }$ \\
\hline & 60 & 2295 & 3323 & 1733 & $\mathrm{x}$ & $\sqrt{ }$ & $\sqrt{ }$ & $\sqrt{ }$ & $\sqrt{ }$ & $\sqrt{ }$ & $\sqrt{ }$ \\
\hline & 175 & 1538 & 2148 & 1147 & $\mathrm{x}$ & $\sqrt{ }$ & $\sqrt{ }$ & $\sqrt{ }$ & $\sqrt{ }$ & $\sqrt{ }$ & $\sqrt{ }$ \\
\hline \multirow[t]{5}{*}{1500} & 0.05 & 3492 & 5372 & 2808 & $\sqrt{ }$ & $\sqrt{ }$ & $\sqrt{ }$ & $\sqrt{ }$ & $\sqrt{ }$ & $\sqrt{ }$ & $\sqrt{ }$ \\
\hline & 20 & 3247 & 4981 & 2637 & $\sqrt{ }$ & $\sqrt{ }$ & $\sqrt{ }$ & $\sqrt{ }$ & $\sqrt{ }$ & $\sqrt{ }$ & $\sqrt{ }$ \\
\hline & 60 & 2857 & 4371 & 2319 & $\sqrt{ }$ & $\sqrt{ }$ & $\sqrt{ }$ & $\sqrt{ }$ & $\sqrt{ }$ & $\sqrt{ }$ & $\sqrt{ }$ \\
\hline & 110 & 2466 & 3785 & 1978 & $\mathrm{x}$ & $\sqrt{ }$ & $\sqrt{ }$ & $\sqrt{ }$ & $\sqrt{ }$ & $\sqrt{ }$ & $\sqrt{ }$ \\
\hline & 200 & 2002 & 3076 & 1611 & $\mathrm{x}$ & $\sqrt{ }$ & $\sqrt{ }$ & $\sqrt{ }$ & $\sqrt{ }$ & $\sqrt{ }$ & $\sqrt{ }$ \\
\hline
\end{tabular}

The fault resistances are given in the column labeled as RF. The columns labeled $R_{43-1}$ and $R_{43-2}$ indicate detection by the local measurement based and communication based protection schemes at $\mathrm{R} 43$ respectively. A tick $(\sqrt{ })$ indicates correct detection while a cross $(\mathrm{x})$ indicates a failure. The columns $R_{34-1}$ and $R_{34-3}$ corresponds to the protection schemes at R34. Columns $I_{R 43}$ and $I_{R 34}$ indicate whether the fault is cleared before the fault current exceed the breaker maximum current at the respective ends. The last column of Table 4 (labeled as S) shows the security of the overall protection and a tick indicates that protection schemes of Cable-14, Cable-24 or bus protection did not incorrectly responded to the fault. The performance of new protection scheme is especially investigated at high fault resistances to evaluate the improvement. Very low resistances faults are applied to check security issues.

According to the results shown in Fig. 6 the peak $|\mathrm{d} v / \mathrm{d} t|$ for a fault with a given fault resistance does not smoothly decrease with the distance from the measuring bus. This is prominent in the case of low resistance faults, and the highest peak $|\mathrm{d} v / \mathrm{d} t|$ is not observed at zero distance, but at a critical distance from the bus. This is due to the voltage doubling effect due to reflected waves and the phenomenon is described in [9]. The same effect can be observed for cables in Tables 8 and 9 . Also, when the fault is very close to the remote end, the remote breaker operates immediately by its local protection and the peak $|\mathrm{d} v / \mathrm{d} t|$ due to breaker operation may become higher than the peak $|\mathrm{d} v / \mathrm{d} t|$ due to fault, especially when the fault resistance is higher. This is evident from the last two rows of Table 4: higher peak ld $v /$ $\mathrm{d} t$ l is observed by R34 for a $200 \Omega$ fault compared to a 110 $\Omega$ fault.

By applying faults on Bus-1, security of the line protection scheme at R14 and fault detection performances of the bus-protection scheme is evaluated. The results are summarized in Table 5. The calculated peak $|\mathrm{d} v / \mathrm{d} t|$ value at line side of the terminal inductor on B14 is much very smaller than bus side. Column $F_{B u s-1}$ indicates the output of the bus protection scheme for Bus-1.

Table 6 shows performances bus protection scheme in the other converter bus, Bus-2. Table 7 summarizes the fault detection performances of the bus-protection scheme applied to the non-converter bus, Bus-4. The calculated peak $|\mathrm{d} v / \mathrm{d} t|$ values at line side of the terminal 
Table 5 Protection performance for Bus-1 during bus faults

\begin{tabular}{lllllll}
\hline$R_{F}(\Omega)$ & \multicolumn{2}{l}{ Peak d $v / \mathrm{d} t(\mathrm{kV} / \mathrm{ms})$ of } & & $F_{\text {Bus }-1}$ & $R_{14 \_1}$ & Max current limit \\
\cline { 2 - 6 } & $V_{1}$ & $V_{14}$ & 48 & $\sqrt{ }$ & $\mathrm{x}$ & $\sqrt{ }$ \\
\hline 0.1 & 4126 & 24 & $\sqrt{ }$ & $\mathrm{x}$ & $\sqrt{ }$ \\
5 & 2979 & 24 & $\sqrt{ }$ & $\mathrm{x}$ & $\sqrt{ }$ \\
50 & 1100 & & & & $\sqrt{ }$ \\
\hline
\end{tabular}

Table 6 Protection performance for Bus-2 during bus faults

\begin{tabular}{|c|c|c|c|c|c|c|}
\hline \multirow[t]{2}{*}{$R_{F}(\Omega)$} & \multicolumn{2}{|c|}{ Peak $\mathrm{d} v / \mathrm{d} t(\mathrm{kV} / \mathrm{ms})$ of } & \multirow[t]{2}{*}{$F_{B u s-2}$} & \multirow[t]{2}{*}{$R_{24 \_1}$} & \multirow[t]{2}{*}{ Max current limit } & \multirow[t]{2}{*}{$\mathrm{S}$} \\
\hline & $V_{2}$ & $V_{24}$ & & & & \\
\hline 0.1 & 4102 & 73 & $\sqrt{ }$ & $\mathrm{x}$ & $\sqrt{ }$ & $\sqrt{ }$ \\
\hline 5 & 2979 & 48 & $\sqrt{ }$ & $\mathrm{x}$ & $\sqrt{ }$ & $\sqrt{ }$ \\
\hline 50 & 1064 & 48 & $\sqrt{ }$ & $\mathrm{x}$ & $\sqrt{ }$ & $\sqrt{ }$ \\
\hline
\end{tabular}

Table 7 Protection performance for Bus-4 during bus faults

\begin{tabular}{|c|c|c|c|c|c|c|}
\hline \multirow[t]{2}{*}{$R_{F}(\Omega)$} & \multicolumn{2}{|c|}{ Peak $\mathrm{d} v / \mathrm{d} t(\mathrm{kV} / \mathrm{ms})$ of } & \multirow[t]{2}{*}{$F_{\text {Bus }-4}$} & \multirow[t]{2}{*}{$F_{43 \_1}$} & \multirow[t]{2}{*}{ Max current limit } & \multirow[t]{2}{*}{$\mathrm{S}$} \\
\hline & $V_{4}$ & $V_{43}$ & & & & \\
\hline 0.05 & 5372 & 2026 & $\sqrt{ }$ & $\mathrm{x}$ & $\sqrt{ }$ & $\sqrt{ }$ \\
\hline 20 & 5201 & 1929 & $\sqrt{ }$ & $\mathrm{x}$ & $\sqrt{ }$ & $\sqrt{ }$ \\
\hline 50 & 4981 & 1758 & $\sqrt{ }$ & $\mathrm{x}$ & $\sqrt{ }$ & $\sqrt{ }$ \\
\hline
\end{tabular}

Table 8 Protection performance during faults on Cable-24

\begin{tabular}{|c|c|c|c|c|c|c|c|c|c|c|c|}
\hline \multirow[t]{3}{*}{ Distance from Bus-4 (km) } & \multirow{3}{*}{$R_{F}(\Omega)$} & \multicolumn{3}{|c|}{ Peak $\mathrm{d} v / \mathrm{d} t(\mathrm{kV} / \mathrm{ms})$} & \multicolumn{4}{|c|}{ Fault detection } & \multicolumn{2}{|c|}{ Max current limit } & \multirow[t]{3}{*}{$\mathrm{S}$} \\
\hline & & \multirow[t]{2}{*}{$V_{42}$} & \multirow[t]{2}{*}{$V_{24}$} & \multirow[t]{2}{*}{$V_{4}$} & \multicolumn{2}{|c|}{$F_{42}$} & \multicolumn{2}{|c|}{$F_{24}$} & \multirow[t]{2}{*}{$I_{R 42}$} & \multirow[t]{2}{*}{$I_{R 24}$} & \\
\hline & & & & & 1 & 2 & 1 & 2 & & & \\
\hline \multirow[t]{2}{*}{0} & 0.05 & 5333 & 6275 & 2384 & $\sqrt{ }$ & $\sqrt{ }$ & $\sqrt{ }$ & $\sqrt{ }$ & $\sqrt{ }$ & $\sqrt{ }$ & $\sqrt{ }$ \\
\hline & 50 & 1076 & 1269 & 333 & $\mathrm{x}$ & $\sqrt{ }$ & $\mathrm{x}$ & $\sqrt{ }$ & $\sqrt{ }$ & $\sqrt{ }$ & $\sqrt{ }$ \\
\hline \multirow[t]{3}{*}{50} & 0.05 & 7051 & 7057 & 2179 & $\sqrt{ }$ & $\sqrt{ }$ & $\sqrt{ }$ & $\sqrt{ }$ & $\sqrt{ }$ & $\sqrt{ }$ & $\sqrt{ }$ \\
\hline & 20 & 1717 & 1733 & 538 & $\mathrm{x}$ & $\sqrt{ }$ & $\mathrm{x}$ & $\sqrt{ }$ & $\sqrt{ }$ & $\sqrt{ }$ & $\sqrt{ }$ \\
\hline & 50 & 1080 & 1005 & 256 & $\mathrm{x}$ & $\sqrt{ }$ & $\mathrm{x}$ & $\sqrt{ }$ & $\sqrt{ }$ & $\sqrt{ }$ & $\sqrt{ }$ \\
\hline \multirow[t]{3}{*}{100} & 0.05 & 6282 & 5523 & 2692 & $\sqrt{ }$ & $\sqrt{ }$ & $\sqrt{ }$ & $\sqrt{ }$ & $\sqrt{ }$ & $\sqrt{ }$ & $\sqrt{ }$ \\
\hline & 20 & 2435 & 2051 & 692 & $\sqrt{ }$ & $\sqrt{ }$ & $\sqrt{ }$ & $\sqrt{ }$ & $\sqrt{ }$ & $\sqrt{ }$ & $\sqrt{ }$ \\
\hline & 50 & 1282 & 1074 & 358 & $\mathrm{x}$ & $\sqrt{ }$ & $\mathrm{x}$ & $\sqrt{ }$ & $\sqrt{ }$ & $\sqrt{ }$ & $\sqrt{ }$ \\
\hline
\end{tabular}

inductors on cables (at B42 and B41) are not included in Table 7 as they were much smaller $(<150 \mathrm{kV} / \mathrm{ms})$.

Although the peak $|\mathrm{d} v / \mathrm{d} t|$ values observed at the line side of L43 during bus faults is higher than the "High-setting" of $\mathrm{R} 43$, the directional properties of the new local measurement based fault detection scheme prevents issuing of trip signals. The performance of the protection schemes for Cable-24 is shown in Table 8 .
The communication based protection is required at both ends of Cable-24. When compared with overhead lines, the peak $|\mathrm{d} v / \mathrm{d} t|$ values observed in cables drop rapidly with the increasing fault resistance. Therefore, the maximum detectable fault resistance in cables is lower than the overhead lines (especially in long cables). However, this is not an issue as high resistance faults are not generally expected in cables. However, high attenuation of wave 
Table 9 Protection performance during faults on Cable-41

\begin{tabular}{|c|c|c|c|c|c|c|c|c|c|c|c|}
\hline \multirow[t]{3}{*}{ Distance from Bus-1 (km) } & \multirow[t]{3}{*}{$R_{F}(\Omega)$} & \multicolumn{3}{|c|}{ Peak $\mathrm{d} v / \mathrm{d} t(\mathrm{kV} / \mathrm{ms})$ of } & \multicolumn{4}{|c|}{ Fault detection } & \multicolumn{2}{|c|}{ Max. current limit } & \multirow[t]{3}{*}{$S$} \\
\hline & & \multirow[t]{2}{*}{$V_{14}$} & \multirow[t]{2}{*}{$V_{41}$} & \multirow[t]{2}{*}{$V_{4}$} & \multicolumn{2}{|c|}{$R 14$} & \multicolumn{2}{|c|}{$R 41$} & \multirow[t]{2}{*}{$I_{R 14}$} & \multirow[t]{2}{*}{$I_{R 41}$} & \\
\hline & & & & & 1 & 2 & 1 & 2 & & & \\
\hline \multirow[t]{3}{*}{0} & 0.05 & 5372 & 1245 & 317 & $\sqrt{ }$ & $\sqrt{ }$ & $\sqrt{ }$ & $\sqrt{ }$ & $\sqrt{ }$ & $\sqrt{ }$ & $\sqrt{ }$ \\
\hline & 20 & 2100 & 488 & 122 & $\sqrt{ }$ & $\sqrt{ }$ & $\sqrt{ }$ & $\sqrt{ }$ & $\sqrt{ }$ & $\sqrt{ }$ & $\sqrt{ }$ \\
\hline & 50 & 1074 & 268 & 73 & $\sqrt{ }$ & $\sqrt{ }$ & $\mathrm{x}$ & $\sqrt{ }$ & $\sqrt{ }$ & $\sqrt{ }$ & $\sqrt{ }$ \\
\hline \multirow[t]{2}{*}{120} & 0.05 & 5909 & 1904 & 463 & $\sqrt{ }$ & $\sqrt{ }$ & $\sqrt{ }$ & $\sqrt{ }$ & $\sqrt{ }$ & $\sqrt{ }$ & $\sqrt{ }$ \\
\hline & 50 & 659 & 219 & 48 & $\sqrt{ }$ & $\sqrt{ }$ & $\mathrm{x}$ & $\sqrt{ }$ & $\sqrt{ }$ & $\sqrt{ }$ & $\sqrt{ }$ \\
\hline \multirow[t]{2}{*}{250} & 0.05 & 3345 & 3345 & 805 & $\sqrt{ }$ & $\sqrt{ }$ & $\sqrt{ }$ & $\sqrt{ }$ & $\sqrt{ }$ & $\sqrt{ }$ & $\sqrt{ }$ \\
\hline & 50 & 390 & 366 & 97 & $\mathrm{x}$ & $\sqrt{ }$ & $\mathrm{x}$ & $\sqrt{ }$ & $\sqrt{ }$ & $\sqrt{ }$ & $\sqrt{ }$ \\
\hline \multirow[t]{3}{*}{380} & 0.05 & 1904 & 5885 & 1391 & $\sqrt{ }$ & $\sqrt{ }$ & $\sqrt{ }$ & $\sqrt{ }$ & $\sqrt{ }$ & $\sqrt{ }$ & $\sqrt{ }$ \\
\hline & 20 & 463 & 1440 & 341 & $\mathrm{x}$ & $\sqrt{ }$ & $\sqrt{ }$ & $\sqrt{ }$ & $\sqrt{ }$ & $\sqrt{ }$ & $\sqrt{ }$ \\
\hline & 50 & 219 & 659 & 170 & $\mathrm{x}$ & $\sqrt{ }$ & $\sqrt{ }$ & $\sqrt{ }$ & $\sqrt{ }$ & $\sqrt{ }$ & $\sqrt{ }$ \\
\hline \multirow[t]{3}{*}{500} & 0.05 & 1245 & 5223 & 1245 & $\sqrt{ }$ & $\sqrt{ }$ & $\sqrt{ }$ & $\sqrt{ }$ & $\sqrt{ }$ & $\sqrt{ }$ & $\sqrt{ }$ \\
\hline & 20 & 488 & 2075 & 488 & $\sqrt{ }$ & $\sqrt{ }$ & $\sqrt{ }$ & $\sqrt{ }$ & $\sqrt{ }$ & $\sqrt{ }$ & $\sqrt{ }$ \\
\hline & 50 & 268 & 1098 & 244 & $\mathrm{x}$ & $\sqrt{ }$ & $\sqrt{ }$ & $\sqrt{ }$ & $\sqrt{ }$ & $\sqrt{ }$ & $\sqrt{ }$ \\
\hline
\end{tabular}

travelling through cables creates a challenge to protect long cables using ROCOV based protection. Table 9 shows the observed performances of the protection scheme for faults on long cable, Cable-14.

According to Tables 8 and 9 , at a relay that protecting a cable, a small value of peak $|\mathrm{d} v / \mathrm{d} t|$ is observed. Therefore, communication assisted protection scheme is very important to increase the sensitivity of the relay without compromising the security.

The proposed algorithms responds when the fault generated travelling waves arrive at its measurement points. Only delays involved are the measurement and filtering delays. The detection times are less than $200 \mu$ s even for the longest transmission line in the case of solid faults. High impedance faults result in longer detection times: for example, it takes about $200 \mu$ s to detect a $50 \Omega$ fault on Cable 14, at $120 \mathrm{~km}$ from B14. If this fault was a solid fault, it is detectable within $50 \mu$ s.

\section{Conclusion}

The paper investigated ROCOV based protection strategies for a simple HVDC grid, and showed that simple ROCOV based protection can fail to detect high resistance faults at locations far from the relay. The side of the fault with respect to the location of the relay can be determined by comparing the peak $|\mathrm{d} v / \mathrm{d} t|$ values observed at two sides of the terminal inductors. Directional element can be used to create a local measurement based fast and secure line protection relay. The communication assisted ROCOV based directional comparison scheme proposed in this paper can be designed to clear high resistance faults before fault currents exceeds the DC breaker limit. In this paper, it is demonstrated that entire spectrum of fault resistances can be covered by using the proposed local measurement based directional ROCOV relay in parallel with a communication assisted two-end ROCOV relay. Importance of communication assisted scheme for cable protection is demonstrated. For a given breaker design and typical MT-HVDC grid, the proposed protection is evaluated and found that protection is capable of clearing faults in any location of the transmission system before breaker current exceeds its rating. The proposed protection scheme can be implemented with practical hardware: a voltage sensor having a bandwidth of $8 \mathrm{kHz}, 32 \mathrm{kHz}$ sampler, and a 12 bit analog to digital converter.

Open Access This article is distributed under the terms of the Creative Commons Attribution 4.0 International License (http:// creativecommons.org/licenses/by/4.0/), which permits unrestricted use, distribution, and reproduction in any medium, provided you give appropriate credit to the original author(s) and the source, provide a link to the Creative Commons license, and indicate if changes were made.

\section{Appendix A}

Overhead Transmission Lines: All overhead DC lines consist of three conductor bundles $30 \mathrm{~m}$ above the ground level in a flat formation, with metallic return conductor at the middle position (Table A1). Each bundle consists of three conductors located in a triangular formation. Two 
Table A1 Voltage source converter parameters

\begin{tabular}{ll}
\hline Parameter & Value \\
\hline Arm inductance & $10 \mathrm{mH}$ \\
Cell DC capacitance & $5100 \mu \mathrm{F}$ \\
Number of levels & 98 \\
DC filter cut-off frequency & $2.4 \mathrm{kHz}$ \\
DC filter MVar & $10 \mathrm{MVA}$ \\
\hline
\end{tabular}

Table A2 Overhead transmission line parameters

\begin{tabular}{ll}
\hline Parameter & Value \\
\hline Conductor radius & $0.06584 \mathrm{~m}$ \\
Ground wire radius & $0.0055245 \mathrm{~m}$ \\
Conductor DC resistance & $0.01061 \Omega / \mathrm{km}$ \\
Ground wire DC resistance & $2.8645 \Omega / \mathrm{km}$ \\
Distance between conductors & $10 \mathrm{~m}$ \\
Bundle spacing & $0.4572 \mathrm{~m}$ \\
Sag & $19.1 \mathrm{~m}$ \\
\hline
\end{tabular}

Table A3 Cable parameters

\begin{tabular}{ll}
\hline Parameter & Value \\
\hline DC resistance & $0.0282 \mathrm{~m} \Omega / \mathrm{km}$ \\
Average ground resistance & $100.0 \Omega / \mathrm{m}$ \\
Conductor radius & $0.0487 \mathrm{~m}$ \\
Inner insulation thickness & $0.01 \mathrm{~m}$ \\
Sheath thickness & $0.0047 \mathrm{~m}$ \\
Outer insulation thickness & $0.008 \mathrm{~m}$ \\
Depth below ground & $1.0 \mathrm{~m}$ \\
Distance between cables & $1.0 \mathrm{~m}$ \\
\hline
\end{tabular}

ground conductors are located $10 \mathrm{~m}$ above main conductors, centred on the tower. Other details are provided in Table A2.

Underground Transmission Lines: All underground DC lines consist of three individual cables buried $1 \mathrm{~m}$ below ground surface in a flat formation, with metallic return conductor at the middle position. Details important for modelling the cables are provided in Table A3.

\section{References}

[1] Hertem DV, Ghandhari M, Delimar M (2010) Technical limitations towards a super-grid-a European prospective. In: Proceedings of IEEE international energy conference, Manama, Bahrain, 18-22 Dec 2010, pp 302-309
[2] Li X, Yuan Z, Fu J et al (2014) Nanao multi-terminal VSCHVDC project for integrating large-scale wind generation. In: Proceedings of IEEE PES general meeting, National Harbor, MD, USA, 27-31 Jul 2014, pp 1-5

[3] Jie Z, Haibin L, Rui X et al (2016) Research of DC circuit breaker applied on Zhoushan multi-terminal VSC-HVDC project. In: Proceedings of IEEE PES Asia-Pacific power and energy engineering conference (APPEEC), Xi' an, China, 25-28 Oct 2016, pp 1636-1640

[4] Merlin MM, Green TC, Mitcheson PD et al (2014) The alternate arm converter: a new hybrid multilevel converter with DC-fault blocking capability. IEEE Trans Power Del 29(1):310-317

[5] Adam GP, Ahmed KH, Finney SJ et al (2013) New breed of network fault-tolerant voltage-source-converter HVDC transmission system. IEEE Trans Power Syst 28(1):335-346

[6] Häfner J, Jacobson B (2011) Proactive hybrid HVDC breakersa key innovation for reliable HVDC grid. In: Proceedings of Cigré symposium, Bologna, Italy, 13-15 Sep 2011

[7] Tahata K, Oukaili E, Kamei S et al (2015) HVDC circuit breakers for HVDC grid applications. In: Proceedings of AC and DC power transmission, Birmingham, UK, 10-12 Feb 2015, pp 1-9

[8] Hajian M, Jovcic D, Wu B (2013) Evaluation of semiconductor based methods for fault isolation on high voltage DC grids. IEEE Trans Smart Grid 4(2):1171-1179

[9] Sneath J, Rajapakse AD (2016) Fault detection and interruption in an earthed HVDC grid using ROCOV and hybrid DC breakers. IEEE Trans Power Del 31(3):973-981

[10] Azad SP, Hertem DV (2017) A fast local bus current-based primary relaying algorithm for HVDC grids. IEEE Trans Power Del 32(1):193-202

[11] Li R, Xu L, Yao L(2016) DC fault detection and location in meshed multi-terminal HVDC systems based on DC reactor voltage change rate. IEEE Trans Power Del PP (99): 1-1

[12] Zhang Y, Tai N, Xu B (2012) Fault analysis and traveling-wave protection scheme for bipolar HVDC lines. IEEE Trans Power Del 27(3):1583-1591

[13] Hajian M, Zhang L, Jovcic D (2015) DC transmission grid with low-speed protection using mechanical DC circuit breakers. IEEE Trans Power Del 30(3):1383-1391

[14] Zheng XD, Tai NL, Yang GL et al (2012) A transient protection scheme for HVDC transmission line. IEEE Trans Power Del 27(2):718-724

[15] Luo S, Dong X, Shi S et al (2016) A directional protection scheme for HVDC transmission lines based on reactive energy. IEEE Trans Power Del 31(2):559-567

[16] He Z, Liu X, Li X et al (2015) A novel traveling-wave directional relay based on apparent surge impedance. IEEE Trans Power Del 30(3):1153-1161

[17] Kong F, Hao Z, Zhang S et al (2014) Development of a novel protection device for bipolar HVDC transmission lines. IEEE Trans Power Del 29(5):2270-2278

[18] Kong F, Hao Z, Zhang B (2016) A novel traveling-wave-based main protection scheme for $800 \mathrm{kV}$ UHVDC bipolar transmission lines. IEEE Trans Power Del 31(5):2159-2168

[19] Leterme W, Beerten J, Hertem DV (2016) Non-unit protection of HVDC grids with inductive DC cable termination. IEEE Trans Power Del 31(2):820-828

[20] Bucher MK, Franck CM (2013) Contribution of fault current sources in multi-terminal HVDC cable networks. IEEE Trans Power Del 28(3):1796-1803

[21] Tahata K, Ka S, Tokoyoda S et al (2014) HVDC circuit breakers for HVDC grid applications. In: Proceedings of 2014 CIGRÉ AORC, Tokyo, Japan, 27-29 May 2014

[22] Li AM, Cai ZX, Sun QZ et al (2009) Study on the dynamic performance characteristics of HVDC control and protections 
for the HVDC line fault. In: Proceedings of IEEE PES general meeting, Calgary, Canada, 26-30 Jul 2009, pp 1-5

[23] Leterme W, Tielens P, Boeck SD et al (2014) Overview of grounding and configuration options for meshed HVDC grids. IEEE Trans Power Del 29(6):2467-2475

[24] Ased GP, Li R, Holliday D et al (2015) Continued operation of multi-terminal HVDC networks based on modular multilevel converters. In: Proceedings of CIGRÉ Lund symposium, Paris, France, 27-28 May 2015

[25] Akhmatov V, Callavik M, Franck CM et al (2014) Technical guidelines and pre-standardization work for first HVDC grids. IEEE Trans Power Del 29(1):327-335

[26] Candelaria J, Park JD (2011) VSC-HVDC system protection: a review of current methods. In: Proceedings of IEEE power systems conference and exposition, Phoenix, AZ, USA, 20-23 March 2011, pp 1-7

Naushath M. HALEEM received the BTec. (Eng) degree from The Open University of Sri Lanka, in 2005, the M.Sc. degree from the University of Manitoba, Winnipeg, MB, Canada, in 2013. He is currently working toward the Ph.D. degree in power systems at the
University of Manitoba. His research interests are multi-terminal HVDC grid protection, hybrid HVDC grid technologies, fault tolerant voltage source converters, fault location in power transmission lines.

Athula D. RAJAPAKSE received the B.Sc. (Eng.) degree in Electrical Engineering from the University of Moratuwa, Katubedda, Sri Lanka, in 1990, the M.Eng. degree in Energy (Energy Technology) from the Asian Institute of Technology, Bangkok, Thailand, in 1993, and the Ph.D. degree in Quantum Engineering \& Systems Science from the University of Tokyo, Tokyo, Japan, in 1998. Currently, he is a Professor at the University of Manitoba, Winnipeg, MB, Canada. His research interests include power system protection, grid integration of distributed and renewable energy systems, and protection of future DC grids. Dr. Rajapakse is a Registered Professional Engineer in the province of Manitoba, Canada. 